\title{
CARTA A JAN DE VOS
}

San Cristóbal de Las Casas, Chiapas, julio 24 del 2011

Querido Jan de Vos:

Hoy me "recordé", como se dice en Chiapas; me desperté, pues, entre el repicar de campanas de las iglesias católicas, los cohetes en honor de san Cristóbal y los estruendosos cánticos en los templos evangélicos de la zona en donde vivo. Me levanté con la intención de disfrutar de un día soleado; estaba tomando mi primer taza de café cuando me dieron la noticia de tu fallecimiento: el día se nubló y me puse triste, pero volvió a alumbrar el Sol. Entonces se abrió el baúl de mi memoria y allí estabas tú.

Te recordé como la última vez que nos encontramos en el centro de la ciudad. Te miré a los lejos con tu andar característico y con tu mirada ávida, tratando de capturar las cambiantes escenas de la ciudad, esta ciudad que han tratado de vender, a propios y extraños, congelada en algún pasado imaginario, cuando quienes la habitamos somos sobrepasados por los cambios vertiginosos que se dan en ella. Fuimos acercándonos porque caminábamos en sentido contrario; de repente me viste y te pusiste en guardia sonriendo, seguramente pensando en la cascada de ironías y sarcasmos que proferiría esta chaparra lépera. Como siempre, nos dio gusto encontrarnos y platicar unos minutos; afectuosamente me preguntaste por mi salud: siempre me sorprendió que en cada uno de nuestros encuentros lo hicieras, nunca te dije lo bien que me hacía sentir tu gentileza.

Me quedé pensando en ti y en tus obras sobre nuestro querido Chiapas, y llegó el mediodía y, con él, el estruendo de cohetes por las vísperas de san Cristóbalito, patrono de esta ciudad que olvidó a Santiago mata moros; por ello te quedaste conmigo y empecé a imaginarte interrogando a fray Pedro Lorenzo de la Nada sobre su vida en estas provincias coloniales, sobre todo aquello que afanosamente buscaste en los archivos y no encontraste; seguramente también te pusiste a llamarle la atención a fray Antonio de Remesal por sus enredos históricos, a los que dedicaste una parte de tu tiempo a desenredar. No lo sé, pero tal vez ahora puedas apreciar en todo su esplendor esa Selva y a su gente que despertaron en ti la pasión por Chiapas, pasión que te arraigó en estas tierras. Selva que te cautivó de tal manera orientando tus empeños para investigar su historia y cómo la codicia insensible de unos pocos provocó la destrucción de buena parte de la riqueza de todos. Tus escritos acerca de esa historia pusieron tu mano en una de las llagas sangrantes de este Chiapas que a tantos nos duele, denunciaste los atropellos y abusos de ayer y hoy; y, no menos importante, recuperaste las voces acalladas de su gente y su floresta. 
Cuantas cosas quisiera decirte, Jan, pero me quedo con el recuerdo de nuestras conversaciones y con tus obras. A éstas las veo como estelas firmemente plantadas (no sólo en suelo chiapaneco) acerca de la historia de Chiapas, muchas de ellas marcando momentos de suma importancia porque son estelas que no fueron escritas por orden de nadie para su vanagloria y beneplácito, sino por tu pasión de historiador. Su fin era profundizar en el pasado de una tierra que te cautivó para siempre, buscando los documentos que narran hechos humanos que marcaron su impronta al configurar nuestro presente. Con tus obras abriste caminos, brechas y senderos que con toda seguridad otros andarán con espíritu crítico y constructivo, dando continuidad al arduo trabajo por ti realizado, avanzando en nuestro conocimiento sobre el ser histórico de Chiapas.

Gracias flamenco-chiapaneco por tu dedicación y esfuerzo, gracias por tus sonrisas. Creo que por eso te llevó la Luna con su sonrisa en el cielo; descansa a gusto y satisfecho por tu fructífera vida. Imposible decirte adiós: por medio de tus obras continuaré dialogando contigo. Fue un placer conocerte y participar contigo en reuniones académicas; por eso con respeto y afecto te digo "hasta luego, Jan”, y te envío las flores del recuerdo con que estás atrapado en mi memoria.

Dolores Aramoni Calderón Universidad Autónoma de Chiapas, Instituto de Estudios Indígenas 